\title{
Are the mangroves in the Galle-Unawatuna area (Sri Lanka) at risk? A social-ecological approach involving local stakeholders for a better conservation policy
}

\author{
S. Mulder ${ }^{1}$, B. Satyanarayana ${ }^{2,3}$, L.P. Jayatissa ${ }^{4} \&$ F. Dahdouh-Guebas ${ }^{2,3}$ \\ ${ }^{1}$ Department of Social Sciences, Wageningen University, Wageningen, The Netherlands. \\ ${ }^{2}$ Laboratory of Systems Ecology and Resource Management, Dept. of Organism Biology, Faculty of Sciences, \\ Université Libre de Bruxelles - ULB, B-1050 Brussels, Belgium. E-mail: fdahdouh@vub.ac.be \\ ${ }^{3}$ Laboratory of Plant Biology and Nature Management, Mangrove Management Group, Vrije Universiteit \\ Brussel - VUB, Pleinlaan 2, B-1050 Brussels, Belgium. \\ ${ }^{4}$ Department of Botany, University of Ruhuna, Matara, Sri Lanka.
}

\begin{abstract}
Despite the known ecological and economic importance of mangrove ecosystems, research is still lacking as to what extent local populations depends on various forest products, or how this might be related to their economic status, age, or gender relations. In present study, the percentage of people depending on such resources in the Galle-Unawatuna area (Sri Lanka) for their subsistence needs was assessed through a survey. The results indicated that local people rely on mangroves to a greater extent for fishery products, fuelwood, and edible plants, than for house/boat construction material, medicinal and other non-timber forest products. All wealth classes (i.e. poor, middle and rich) use the resources, although greater dependency of the poor is common. A positive linear relationship, although not significant $\left(\mathrm{R}^{2}=0.22 ; P=0.69\right)$, was observed between people's age ( $\geq 40$ years) and mangrove resource use, along with a gendered division of labour. In addition, the use of mangrove resources is not necessarily poverty-driven: preference and tradition also play important roles. However, the physical infrastructure developments (i.e. construction of a cement factory, dam and road) have had several negative impacts ranging from water quality deterioration and dynamic shifts in mangrove vegetation to reduced fish production in the vicinity. Given our results, amendments to the existing rules governing forest conservation are recommended in order to provide long-term benefits for local livelihoods as well as ecosystem.
\end{abstract}

\section{Keywords}

Galle-Unawatuna, natural resources, infrastructure, coastal development, socio-economics, Sri Lanka, stakeholder, ethnobiology, management 